\title{
Effect of weather conditions on rheumatic patients
}

\author{
Daniela Guedj, Abraham Weinberger
}

\begin{abstract}
In a one month prospective study of 62 rheumatic patients-16 with rheumatoid arthritis (RA), 24 with osteoarthritis (OA), 11 with inflammatory arthritis, 11 with fibromyalgia joint pain-swelling and everyday activity was compared with changes in daily weather conditions. In most patients weather changes increased arthritic symptoms. Women were more sensitive to weather than men $(62 \% v 37 \%)$. Pain was affected positively by barometric pressure and temperature in RA, by temperature, rain, and barometric pressure in $\mathrm{OA}$, and by barometric pressure in fibromyalgia. These results support the belief of most rheumatic patients that weather conditions significantly influence their day to day symptoms.
\end{abstract}

Information about the effect of barometric pressure, humidity, and temperature on rheumatic diseases has been little reported. Opinions reflected in the few studies discussing the subject are not unanimous. Earlier studies, using climate control rooms, indicated that rheumatic symptoms were unaffected if weather conditions were held constant or if only one of the variables temperature, humidity, or barometric pressure were altered. ${ }^{12}$ Raising the humidity and lowering the pressure simultaneously, however, led to the appearance of some rheumatic symptoms. Two recent observations are contradictory. One study indicated that external weather conditions do not influence the day to day symptoms of arthritis in patients with rheumatoid arthritis $(\mathrm{RA})$ and osteoarthritis (OA), whereas other investigators found a significant influence of meteorological factors on rheumatic pain in patients with RA. ${ }^{34}$

The purpose of this study is to re-evaluate the effect of weather conditions on patients with various rheumatic diseases and to extend it to patients with fibromyalgia.

Rheumatology Unit, Beilinson Medical Center, Petah Tikva and Sackler School of Medicine Tel Aviv University, Israel D Guedi A Weinberger

Rheumatology Service, Netanya, Israel D Guedj

Correspondence to: Professor A Weinberger, Rheumatology Unit, Beilinson Medical Center, Petah Tikva 49 100, Israel. Accepted for publication 6 June 1989 errors in filling out the form, probably becau of difficulty in understanding. Of the patients studied, 50 were women and 12 men. All 62 patients taking part in this study were inhabitants of the mid-coastal plain of Israel.

\section{Patients and methods}

sent, 62 were completed and are included in this study. Seventeen patients did not return to the clinic and were lost to follow up, 26 missed days
Sixteen patients (mean age $55 \cdot 7$ years) had RA; 11 patients (mean age 46.4 years) had various inflammatory arthritides: undefined polyarthritis (five), psoriatic arthritis (three), Behçet's disease (two), systemic lupus erythematosus (one); 24 patients (mean age 61 years) had $\mathrm{OA}$, and 11 patients (mean age 44 years) fibromyalgia.

Rheumatoid arthritis was diagnosed according to the criteria of the American Rheumatism Association. ${ }^{5}$ All patients with OA had typical joint symptoms and radiological evidence of joint space narrowing and osteophyte formation. Patients with fibromyalgia had trunk or limb pain accompanied by tenderness. All had characteristic tender points. ${ }^{6}$

The questionnaire required information about the severity of the joint pain and swelling as follows: $0=$ free of pain or swelling; $1=$ pain or swelling, or both; $2=$ extreme pain or extreme swelling, or both. In addition, the patient had to note his everyday activity ability level as normal $=0$, with help or supportive device $=1$, or unable to help self $=2$. Scoring was done every morning. Atmospheric pressure, relative humidity, temperature degrees, and rains were recorded daily by us between 5 January 1987 and 23 May 1987.

A statistical analysis was used with the statistical package for the social sciences (SPSS) computer program to analyse data. The $\chi^{2}$ test was used to compare pain and swelling in joints with meteorological factors in univariate analysis. Multivariate regression analysis was used to identify weather condition variables that had significant independent associations with joint pain and swelling. Prediction rate of rain and pain was by discriminant analysis. All calculated $p$ values are two tailed.

\section{Results}

Morning weather conditions during the study were changeable: temperature ranged from $8^{\circ} \mathrm{C}$ to $27^{\circ} \mathrm{C}$, barometric pressure from 1007 to 1025 mbar, and relative humidity from 39 to $96 \%$.

Four of 16 (25\%) patients with RA and 20/24 (83\%) patients with OA were sensitive to weather-that is, weather changes increased arthritic symptoms, while $7 / 11(64 \%)$ patients with inflammatory arthritis were affected by the meteorological conditions. Eight of 11 (77\%) patients with fibromyalgia reported that one or more of the weather conditions changed their score rate.

More women than men were sensitive to weather $(62 \% v 37 \%)$. There was no difference 
Prediction rate of rain and pain*

\begin{tabular}{|c|c|c|c|c|}
\hline Disease & $\begin{array}{l}\text { Number } \\
\text { of days } \\
\text { evaluated }\end{array}$ & $\begin{array}{l}\text { Variables } \\
\text { for paint }\end{array}$ & $\begin{array}{l}\text { Prediction } \\
\text { rate of } \\
\text { rain }(\%)\end{array}$ & $\begin{array}{l}\text { Prediction } \\
\text { rate of } \\
\text { pain }(\%)\end{array}$ \\
\hline $\begin{array}{l}\text { Rheumatoid } \\
\text { arthritis }\end{array}$ & 502 & $\begin{array}{l}\text { Temp } \\
\text { Bar }\end{array}$ & $75 \cdot 9$ & $51 \cdot 7$ \\
\hline Osteoarthritis & 688 & $\begin{array}{l}\text { Temp } \\
\text { Bar } \\
\text { Rain }\end{array}$ & $80 \cdot 0$ & $57 \cdot 6$ \\
\hline $\begin{array}{l}\text { Inflammatory } \\
\text { arthritis } \\
\text { Fibromyalgia }\end{array}$ & $\begin{array}{l}326 \\
334\end{array}$ & $\overline{\mathrm{Bar}}$ & $\begin{array}{l}76 \cdot 6 \\
82 \cdot 6\end{array}$ & $\begin{array}{l}55 \cdot 6 \\
57.8\end{array}$ \\
\hline
\end{tabular}

${ }^{*}$ Discriminant analysis method.

$\dagger$ Temp=temperature; $\mathrm{Bar}=$ barometric pressure

in age and weight between groups sensitive or insensitive to weather.

When discriminant analysis was used rain could be predicted in $\mathrm{OA}$ and fibromyalgia by $80 \%$ and $83 \%$ respectively. This statistical analysis allowed for prediction of rain in RA and in inflammatory arthritis by $76 \%$ and $77 \%$ respectively (table).

The association between pain and rain was analysed in each disease. Significance between the two was found only in OA: pain was significantly increased among patients with $\mathrm{OA}$ on days of rain $\left(\chi^{2}=11.6796 ; p=0.0006\right)$.

When the association between pain and meteorological variable was examined with discriminant analysis it emerged that pain as a dependent variable was affected positively by barometric pressure and temperature in RA $(p<0.05)$ and by temperature, rain, and barometric pressure in OA $(p<0.05)$. Pain was also affected positively by barometric pressure in fibromyalgia $(\mathrm{p}<0.05)$.

When score was the dependent variable the barometric pressure predicted significantly $(p<0.05)$ the score in all groups of patients (multiple regression analysis, positive correlation).

\section{Discussion}

Previous studies have reported the adverse effect of climatic changes on arthritis; however, reports have been anecdotal. Attempts to study weather effects on arthritis objectively and in a laboratory setting have been few. As early as 1948 Edstrom showed that patients with RA improved significantly when living continuously in a room kept constantly warm and dry. ${ }^{1}$ Later, Hollander et al, using a controlled climate chamber, indicated that arthritis of RA and OA often worsened within a few hours of the onset of a combined rise in humidity and fall of barometric pressure, whereas single variations of climatic variables did not have this effect. ${ }^{27}$ In Edstrom's study the number of patients was small, however, and no attempts were made to control barometric pressure or to evaluate the effects of changing meteorological conditions. Hollander, on the other hand, investigated the weather variables but in a small group of patients for a comparatively short period of time. In our study, in a larger number of patients over a period of 30 days, we found that pain was affected positively by temperature, rain, and barometric pressure in OA and that an increase in barometric pressure and temperature intensified the arthritic pain of RA.

The results of a year's study by Patberg et $a l^{3}$ of 88 patients with RA tend to confirm Hollander's observation, which showed that weather changes produced worsening of arthritic symptoms and signs and that increasing humidity and falling barometric pressure produced increased arthritic pain, swelling, and stiffness. Sibley, on the other hand, in a study of a slightly smaller series of patients with RA and OA over a period of a month, concluded that no significant correlation was shown between weather and arthritic symptoms. ${ }^{4}$ Further studies are needed to resolve this question conclusively.

Many patients with fibromyalgia noted that weather changes aggravated their pain. This phenomenon, however, was not studied extensively in this syndrome. Exposure to cold, wet, and sudden changes in weather may precipitate or aggravate their rheumatic symptoms by mechanisms not fully understood. ${ }^{8}$ Years ago, Kellgren noted that when deep hyperalgesia was present even slow cooling of the affected part caused severe and prolonged pain. ${ }^{9}$ Our results, on the other hand, suggest that pain was influenced by barometric pressure alone in patients with fibromyalgia.

It is interesting that pain in rheumatic disease may be predicted in a high percentage of patients when one or more of the climate variables is used. This observation is in accordance with most of the statements of rheumatic patients that they can predict weather changes by increased joint pain.

We thank Nava Jelin for statistical help with this study.

1 Edstrom G. Investigations into the effect of a hot, dry microclimate on the peripheral circulation, etc., of arthritis patients. Ann Rheum Dis 1948; 7: 76-92.

2 Hollander J L. The controlled climate chamber. Trans $N Y$ Acad Sci 1961; 24: 167-72.

3 Patberg W R, Nienhuis R L F, Veringa F. Relation between meteorological factors and pain in rheumatoid arthritis in a marine climate. $\mathcal{F}$ Rheumatol 1985; 12: 711-5.

4 Sibley J T. Weather and arthritis symptoms. $\mathcal{F}$ Rheumatol 1985; 12: 707-10.

5 Ropes M W, Bennett G A, Cobb S, Jacox R, Jessar R A. 1958 Revision of diagnostic criteria for rheumatoid arthritis. Arthritis Rheum 1959; 2: 16-20.

6 Yunus M, Masi A T, Calabro J J, Miller K A, Feigenbaum S L. Primary fibromyalgia (fibrositis). Clinical study of 50 patients with matched normal controls. Semin Arthritis Rheum 1981; 11: 151-71.

7 Hollander J L, Yeostros S J. The effect of simultaneous variations of humidity and barometric pressure on arthritis. Bulletin of the American Meteorological Society 1963; 44: Bulletin

8 Smythe H A. Nonarticular rheumatism and psychogenic musculoskeletal syndromes. In: McCarty D J, ed. Arthritis and allied conditions. 10th ed. Philadelphia: Lea and Febiger, 1985: 1083.

9 Kellgren J H. Deep pain sensibility. Lancet 1949; i: 943-9. 